\title{
PROF. BORDEWIJK CONTRA OPPENHEIMER EN SAX.
}

In de Economist van Januari en Februari 1920 en 1922 verschenen van de hand van Prof. $H$. W. C. Bordewijk eenige artikelen, onderscheidenlijk getiteld ,von Böhm of Sax ?” (I) en „Robinson als rentetrekker" (II) en beide gericht tegen het belangrijke boek van Prof. Emil Sax „Der Kapitalzins, Kritische Studiën", waarin de bekende rentetheorie van von Böhm Bawerk werd bestreden. In het eerste artikel had de Groningsche hoogleeraar zich ten doel gesteld, ,de al of niet houdbaarheid van von Böhm's renteleer, en in het bijzonder van zijn drie gronden, te onderzoeken naar aanleiding van de campagne, door Sax daartegen gevoerd." De slotson van Prof. Bordewijk was, dat, afgezien van het punt der zgn. voegingswaarde bij den technischen faktor, waar z.i. wellicht volle klaarheid nog niet was bereikt, von Böhm's leergebouw zich nog steeds veilig op zijn drie peilers verheft. Intusschen, de hoogleeraar gevoelde zelf, dat zijne kritische studie niet volledig was en zegde o.a. aan het slot van zijn artikel een nadere bespreking van het positief cleel van Sax' boek toe, waarin de vraag wordt behandeld, of de kapitaalrente al dan niet in de „Wirtschaft Robinson's" kan voorkomen. Het tweede artikel voldoet aan de gedane toezegging. In tegenstelling met Sax komt Prof. Bordewijk tot de konklusie, dat de rente een natuurlijke categorie is, die wel degelijk ook in de huishouding van Robinson voorkont.

Tusschen de tijdstippen van publikatie der voomoemde artikelen in, verscheen het artikel „Het monopoliebegrip bij Franz Oppenheimer in verband met zijn uitbuitingsleer", (III), waarin Prof. Bordewijk te velde trok tegen enkele denkbeelden van zijnen Frankfortschen ambtgenoot. Ik stel mij voor, voornoemde artikelen hieronder aan eene kritische bespreking te onderwerpen; ik zal ze citeeren als I, II en III. Alvorens hiertoe over te gaan, schijnt het mij gewenscht in het kort eenige belangrijke punten van overeen- 
woordig en toekomstgoed erkent. Alleen stelt Sax voor von Böhm's „drei Gründe" er andere in de plaats. Deze questies schijnen mij evenals andere psychologische meeningsverschillen van von Böhmi en Sax, nog steeds niet tot volkomen klaarheid gebracht. Gemakshalve zal ik echter met Prof. Bordewijk, wiens scherpzinnige kritiek op Sax' kritiek der "drei Gründe" allen lof verdient, de juistheid van von Böhm's ,drei Gründe" aannemen. Strikt genomen wordt dus het artikel ,von Böhm of Sax ?" niet in onze kritiek betrokken.

Met nadruk breng ik naar voren, dat de kritjek van Prof. Bordewijk zich bepaalt tot geschilpunten 1 en 3; 2 en vooral 4 bleven buiten beschouwing. Zoowel in mijn proefschrift als in eenige artikelen in de Economist, heb ik getracht de juistheid van deze stellingen te bewijzen en tevens de daarmede strijdige burgerlijke theorieën te weerleggen. Ik betreur het, dat mijn tegenstander, hoewel hij van mijn proefschrift blijkt te hebben kennis genomen, op deze bewijzen en weerleggingen met geen enkel woord ingaat. Zélfs neemt de hoogleeraar op blz. 596 van zijn tegen Oppenheimer gericht artikel een standpunt in, waarvan ik, in mijne kritische bespreking van Schumpeter's zienswijze, uitvoerig de onjuistheid meen te hebben aangetoond. Ik ben tengevolge daarvan, zeer tot mijn leedwezen, gedwongen in herhaling van vroegere betoogen te vervallen. Het spreekt voorts vanzelf, dat zoolang de verdedigers der burgerlijke economie en de aanvallers van het liberale socialisme niet zorgvuldiger rekening houden met hetgeen door de tegenpartij te berde is gebracht, het voor derden niet mogelijk is, ten aanzien van de belangrijke twistpunten dezer scholen, hunne houding te bepalen.

In dit verband zij er ook de aandacht op gevestigd, dat de kritiek tegen Sax enkel betrekking heeft op de blz. $1 \mathrm{t} / \mathrm{m} 97$ van zijn $249 \mathrm{blz}$. beslaand boek, terwijl de kritiek tegen Oppenheimer zich bepaalt tot een enkel bestanddeel van zijn aan belangrijke denkbeelden rijk stelsel. Ik geloof derhalve, dat ik mijnen hooggeleerden tegenstander geen onrecht aandoe, als ik zijn kritieken als zeer onvolledig beschouw, een onvolledigheid, die ik te meer betreur, omdat, in tegenstelling met het slot van ,von Böhm of Sax" geen enkele uitlating van den schrijver grond geeft nadere vervolgkritieken te verwachten. Maar laten wij niet desespereeren. Alle goede dingen bestaan in drieën en wij leven daarom in de hoop, dat nog ten minste één nadere kritiek op Sax en twee nadere kritieken op Oppenheimer zullen verschijnen, waarin Prof. 
Bordewijk zal doen, hetgeen tot dusver werd nagelaten. Moge hij dan tevens met den inhoud van dit artikel rekening houden.

De vraag of de rente al dan niet in de huishouding van Robinson kan voorkomen, acht de hoogleeraar, blijkens blz. 9 van I en de blz. 1 en 2 van II van zeer groot, o.i. van een te groot gewicht. $\mathrm{Hij}$ spreekt van een ,stelling van theoretische en politieke strekking" en acht ,,voor het sociaal-politieke oordeel over de rente en over het rentegenot door partikuliere kapitaalbezitters de vraag, of Robinson rente genieten kon, van het allergrootste belang". O.i. geheel ten onrechte. De uitbuitingsthcorie staat noch valt met den rentetrekkenden Robinson, doch met de in den loop der historie vooral mede door onrecht veroorzaakte bezitskoncentratie. Dezc bezitskoncentratie verandert natuurlijk niets aan het feit, dat ook in de tegenwoordige maatschappij het renteinkomen voortspruit uit ruil van tegenwoordige tegein toekomstgoederen, maar wel heeft zij ten gevolge, dat dit rente-inkomen enkel wordt genoten door een relatief kleine groep bezitters ten koste van een groote groep niet-bezitters. Bij gelijkmatiger rijkdomsverdeeling, bij een ontwikkeling op grond enkel van arbeid en ruil, zou de rentestand lager en het aantal duurzaam van anderen rentetrekkenden kleiner zijn geweest. De meesten zouden - net als Robinson - van zich zelf ",rente" trekken. Dit en niets anders bedoelt èn Oppenheimer en ik met de uitbuitingstheorie. Deze theorie - alchus opgevat is dus zeer wel vereenigbaar met het uitgangspunt der agio-rentetheorie. Omgekeerd is echter een verwerping der uitbuitingsleer niet vereenigbaar met een erkenning van in den loop der historic gèpleegd onrecht.

Zooals reeds gezegd zijn Prof. Bordewijk en ik het over de psyche van Robinson geheel eens. Dit blijkt uit het door Prof. B. op blz. $115 \mathrm{v}$. van II aangehaalde citaat uit mijn proefschrift, waarvan hij enkel het slot bestrijdt. Onder deze omstandigheid moet de vraag of Robinson al dan niet rentetrekker is zich oplossen in een questie van definitie. Prof. Bordewijk stelt de rente gelijk met agio van tegenwoordig over toekomstgoed. Dit agio heb ik nimmer bij Robinson ontkend, ja zelfs, blijkens het door Prof. Bordewijk aangehaald citaat, uitdrukkelijk toegegeven. Ik acht echter de gelijkstelling van agio met rente om $a$ ) historische, $b$ ) theoretische en $c$ ) praktische gronden ongeoorloofd en beschouw daarom de rente als een vorm van arbeidsloos inkomen, 
grond. Dit klemt te meer, omdat uit het door Prof. B. zelf aangehaald citaat uit mijn proefschrift (II blz. 115) overtuigend blijkt, dat ik er nimmer aan dacht het agio, d.i. wat Prof. B. de oorspronkelijke kapitaalrente gelieft te noemen, in het huishouden van Robinson te ontkennen. En vandaar, dat de leemte, die Prof. $B$ in mijn proefschrift meent te konstatecren, niet aanwezig is. Want ik leid het niet-voorkomen van de rente (in den door mij bedoelden zin) nict af uit een eventueele verwerping der ,drei Gründe", maar enkel uit een m.i. juister rentedefinitie. Het pleit niet voor een nauwgezette overweging van mijne pennevruchten, dat Prof. B. dit niet heeft ingezien. Evenmin pleit daarvoor, dat hij mij op blz. 116 van II het syllogisme verwijt: ,rente is uitbuiting, waartoe bezit in staat stelt; Robinson kan in zijn eentje niet uitbuiten; dus wat er overigens ook zij van een meer-opbrengst in produkt en in waarde bij productie langs omwegen, dit resultaat kan nict als rente worden aangemerkt. Het is geen arbeidsloos inkomen". En dat, terwijl ik op blz. 270 v. van mijn proefschrift uitdrukkelijk tegen de liberale socialisten in, de mogelijkheid van rechtvaardige, niet uit uitbuiting voortvloeiende rente verdedigde !! Het eigenaardige van mijn standpunt is juist, dat ik die mogelijkheid met de burgerlijke theoretici toegeef en toch met de socialisten vasthoud aan het feit, dat de rente gevolg is van bezitsverhoudingen. Op grond van de bezitskoncentratie en het historisch ontstaan der bestaande bezitsverhoudingen, op geene andere gronden, ben $\mathrm{ik}$ aanhanger van de uitbuitingstheorie. Ik heb dus recht tot de uitspraak, dat Prof. B. er niet in is geslaagd tot den kern van mijne denkbeelden door te dringen. $\mathrm{lk}$ vrees, dat. dit niet aan mij ligt, want ik heb ze meer dan eens, ja vaker, dan ik oorbaar achtte, duidelijk uiteengezet. Ook betreur ik, dat Prof. B. met geen enkel woord ingaat op mijn belangrijke, uit de praemissen van von Böhm-Bawerk's theorie afgeleicie stelling: "hoe gelijkmatiger de rijkdomsverdeeling, hoe lager de rentestand, des te grooter de voortbrenging." Een reden te meer voor mij, de kritiek van Prof. B. onvolledig te achten. Ook voor het koketteeren met de zgn. rente (in werkelijkheid het agio) in den socialistenstaat (blz. 3 van II) is geen grond, zoolang de contra-beschouwingen van Sax (o.a. blz. 214 v.) niet zijn weerlegd.

Een enkel woord over de zgn. toerekeningtheorie, waarvan Prof. B. zegt, dat ze, aangevuld met de agio-leer een gemotiveerd antwoord geeft op de vraag of Robinson enkel arbeidsinkomen 
dan wellicht ook ,,arbeidsloos" inkomen zal genieten. In de eerste plaats zij aangeteekend, dat Prof. B. met geen enkel woord ingaat op de kritiek door Sax tegen de samenkoppeling dezer onvereenigbare theorieën uitgeoefend (o. c. blz. 95, 196), noch op de in denzelfden zin luidende opmerkingen, voorkomend op blz. $292 \mathrm{v}$. van mijn proefschrift. Evenmin nam Prof. B. nota van de op blz. 625 voorkomende beschouwing van het eerste deel van mijn artikel in de Economist „Oppenheimer en zijne bestrijders". Ik schreef daar, dat het resultaat van de productie langs omwegen, indien het eenmaal is bereikt, niet alleen meer waard zal zijn dan het resultaat der directe produktie doch ook dan de kontante waarde. waarop het, op het tijdstip der keuze, werd geschat en noodigde in een noot de voorstanders van den rentetrekkenden Robinson uit, eens nauwkeurig te willen preciseeren, wat ze als Robinson's rente beschouwen. Met leedwezen stel ik vast, dat. Prof. B. aan mijn verzoek niet heeft voldaan.

Voorts schreef ik o.a.: „Evenmin gaat het aan, deze verschillen aan Robinson's kapitaal toe te rekenen. Robinson zelf denkt aan eene dergelijke toerekening niet, daar ze economisch voor hem zonder belang is. Ook zonder toepassing toch der toerekeningstheorie is hij volkomen in staat zijn arbeidskracht op de doelmatigste wijze aan te wenden. (Het grootste kontante verschil van kontante baten en lasten geeft den doorslag). Bovendien kan hij die theorie niet begrijpen. Gesteld, dat het jagen hem als regel meer oplevert dan het visschen. Is dat voor hem een reden die meerdere opbrengst aan zijn verstandige keuze van arbeidswijze en de rest aan zijn arbeid in het algemeen toe te rekenen ? Zeer zeker niet. Welnu, evenmin zal Robinson het begrijpen, dat een meerdere opbrengst van de productie langs omwegen aan ee! tusschenprodukt van dien omweg moet worden toegerekend. Het gaat in al deze gevallen om verschillende resultaten van verschillende arbeidswijzen". Op blz. 110 v. van II stelt Prof. Bordewijk - zonder echter op voornoemden passus in te gaan: „Technisch beschouwd hebben grond en arbeid saamgewerkt om de opbrengst en dus ook.de meeropbrengst te verkrijgen. Maar... de vergelijking met de opbrengst van het minder vruchtbare grondstuk doet zien, waaraan de meeropbrengst van het eerstbedoelde land te danken is: de betere qualiteit.... Al brengt die grond zonder arbeid ook niets voort, zoo is het niettemin een economische waarheid, dat die grond het opbrengstverschil heeft 
monopolie-begrip en zijn standpunt inzake het verschil tusschen potenticele en feitelijke welvaart niet aanwezig is.

Tot dezelfde slotsom voert de bestudeering van den ontwikkelingsgang van $O$.'s stelsel. Op blz. 139 van mijn boek schreef ik: „De kern van O.'s liberale socialisme is reeds in zijn eerste werken (Siedlungsgenossenschaft, Grossgruncleigentum und soziale Frage) aan te treffen; de organische hypothese, symptomatologie en aetiologie, diagnose en therapie der sociale krankheid zijn daarin duictelijk uiteengezet. Oppenheiner's economische ontwikkeling verliep zonder groote schokken, bracht geene verandering in zijn gronddenkbeelden, doch voerden tot hunne kritische verdediging, theoretische verscherping en systematischen uitbouw." Een dergelijke theoretisch-terminologische verscherping is O.'s monopolic-begrip. Het komt in die oudere werken in 't geheel niet voor, doch verschijnt voor het eerst in de "Theorie der reinen und politischen Oeconomie" ten toonecle. In ,Wertund Kapitalprofit", werkte O. zijn waarde- en monopolie-theorieün nader uit. Het typische verschil van O.'s monopolie-begrip met dat van de burgerlijke theoretici is, dat $O$ ook dan van een monopolie spreekt indien onverneerderbare goederen zonder uitdrukkelijke of stilzwijgende sanenspanning der aanbieders, tei markt worden gebracht. Dat ook in een dergelijk geval - evenals bij de onbetwiste monopolie-gevallen - het verband tusschen winst en kosten is verbroken, daar van de groote winsten geen prikkel tot vermeerderde produktie kan uitgaan, wordt door niemand geloochend. Ik kon dan ook terecht op blz. 250 van mijn proefschrift schrijven, dat de strijd Oppenheimer-Schumpeter over de definitie van monopolie cen terminologische questie zonder eenige werkelijke beteekenis was. Aan een zuiver terminologisch twistpunt zulke verstrekkende gevolgen te verbinden gaat niet aan. Wie O.'s stelsel wil bestrijden, peutere niet aan zijn monopoliebegrip, doch richte zijn aanval in le eerste plaats op zijn ,, Theoric des einseitigen Druckes". Deze theorie noemde ik (o.c. blz. 220. noot 37) ,wellicht de belangrijkste deduktie der gansche theoretische economie". Het moet dus voor cen voorstander eener deduktieve economie als Prof. Bordewijk ongetwijfeld is, eene groote bekoring hebben, aan eene weerlegging dier voor het liberale socialisme fundamenteele deduktie zijne krachten te beproeven. Wij vreezen echter, dat hij op graniet zal bijten.

Met Schumpeter wil Prof. Bordewijk de beperkte konkurrentie 
normale, de kapitalist en de grondeigenaar minder dan normale welvaart zou genieten, was er geen enkel beletsel voor kapitalisten of grondeigenaars ook arbeider te worden. Werdra zou een volkomen welvaartsnivelleering hebben plaats gegrepen, terwijl thans, nu kapitalisten en grondeigenaars méér dan gewone en de arbeiders minder dan gewone welvaart genieten, die welvaarts.nivelleering niet kan plaats grijpen, daar de bestaande eigendomsverhoudingen die strooming naar het evenwicht verhinderen. Met ieder arbeider, die wil, kan en mag kapitalist of grondeigenaar worden. Daarin bestaat juist de ,monopolie-achtige" positie der kapitalisten en grondeigenaars". Moge Prof. Bordewijk met deze opmerkingen nog eens rekening houden. Waarschijnlijk zal hij dan niet meer durven volhouden, dat het kapitaal (beter d: kapitalist) afhankelijker is van den arbeider dan omgekeerd (II blz. 112 v.).

Bij zijne kritiek van O.'s stelling inzake de kunstmatige rentabiliteitsbeperking der voortbrenging sluit Prof. Bordewijk zich aan bij een boekje van H. Oswalt ,Falsche Rechnungen”, eene in 1917 geschreven ,kritische Auseinandersetzung mit der Oppenheimerschen Theorie". O. antwoordde met een door Prof. B. niet vermelde antikritiek ,Falsche Rechnungen ?” terwijl Oswalt repliceerde met een eveneens door Prof. B. niet vermelde brochure „Keine falschen Rechnungen ?" Prof. B. is tot mijne niet geringe verbazing van oordeel, dat de eerste brochure van Oswalt tot het merg van O.'s stelsel doordringt en daarmede, in groote trekken ,endgültig" afrekent. Onze indruk van bedoelde brochure is minder gunstig; met $O$. beschouw ik haar als ,eine verunglückte Streitschrift". In deze meening staan wij niet alleen; ook Budge blijkt in zijn nieuwste boek - althans eenigermate - het onvoldoende van Oswalt's kritiek te hebben ingezien. Hij schrijft: „Am meisten Beachtung verdient die Kritik, die ganz neuerdings Oswalt Oppenheimer hat zuteil werden lassen. Leider hat er dieser Kritik nur eine populäre Kampfschrift seines Gegners zugrunde gelegt, und seine Einwendungen treffen daher nur eine Reihe Einzelbehauptungen O.'s nicht aber dessen gesamtes system (ik cursiveer). Auch geht er von der Ausicht aus, O. habe den Monopoltribut, durch dessen Zahlung der Arbeiter ausgebeutet werde, in der Grundrente erblickt. Das gilt nicht von O.'s Lehre in ihrer heutigen, endgültig abgeschlossenen Gestalt. Zu Unrecht leugnet Oswalt den Charakter der Grundrente als eines Monopolpreises. 
Schlieszlich greift er O. mit einem Argumente an, mittels dessen dieser keineswegs getroffen werden kann. Er behauptet, die Tatsache, dasz der Konsument Profit und Grundrente zahlt, beweise, dasz beide Einkommenszweige das Entgelt fuer irgendein wertvolles Gut sein miiszten .... Dieser Vorwurf kann aber Opp. nicht gemacht werden, demn bei ihm ist der Mehrwert ein Bestandteil des natürlichen Arbeitslohnes, des statischen Preises der Arbeit, der von Kapitalisten dem Arbeiter infolge eines Monopolverhältnisses auf den Markte der Dienste entrissen wird. Er ist also unter allen Uniständen Kostenbestanclteil und musz vom Konsumenten ersetzt werden, gleichgültig, ob er clem Arbeiter oder dem Kapitalisten zufällt”. „Die Kritiken, die die O.'sche Lehre seither erfahren hat, haben das System als ganzes nicht getrotfen." (ik cursiveer).

Aldus terecht Budge, die zelf een poging tot „endgültige” weerlegging in zijn boek beprocfde. Met welk succes moge de lezer uit mijne kritische bespreking in de Economist van November en December 1921 leeren.

Houdt men bij de lezing vall Oswalt's brochures bovenstaand citaat uit Budge voor oogen en let men er voorts op, dat Oswalt, cvenals Budge zelf, nog de oude, door Böhm ,endgültig” weerlegde "Nutzungstheorie" der rente aanhangt, dan zal men de onjuistheid van het gunstig oordeel van Prof. B. helder inzien. Opgemerkt zij nog, dat Oswalt evenmin als Prof. Bordewijk met de bezwaren rekening houdt, in (it artikel uiteengezet. 1)

Tegenover de kritiek van Prof. B. merk ik in de eerste plaats op, dat deze verzuimt geschilpunt 4 (in het begin van dit artikel genoem() te weerleggen.

Op den heilzamen kant van het sparen vestigde ik op blz. 130 noot 46 van mijn boek uitdrukkelijk de aandacht.

Inderdaad, de loonen in de bouwvakken zijn zeer hoog gestegen. Men wist dit aan het Departement van Financiën reeds lang. Maar wat bewijst deze - zuiver dynamische - stijging tegen het liberaal-socialistisch stelsel en zijn statische monopolie- en rentetheorie?

Ten slotte nog een enkel woord over het gevoelsargument,

1) Evenmin doet dit - helaas - Prof. D. van Blom in zijn overigens van een eerlijk streven naar objektiviteit getuigend, zoo juist verschenen artikel over „Socialisatie”. 
waarmede Prof. B. zijin artikel besluit. Met een beroep op de treurige ervaringen van de bezitters van Russische effecten betoog: de hooggeleerde schrijver, dat het geloofsartikel der uitbuiting tot het plegen van het grofste onrecht heeft geleid. „Waar onder onzi oogen duizenden en tienduizenden lijden onder het annuleeren van de Russische schuld, daar dringt zich met macht het gevoel op, dat het uitbuitingskarakter cler rente wel onomstootelijk, d.i. wetenschappelijk mag vast staan, voor en aleer op zóó ruwe wijze in het bestaan van talloos velen wordt ingegrepen". Het is fraai. Wat zou men zeggen van dezen zin als pendant: ,De onmogelijkheid van eene betere maatschappij mag wel onomstootelijk, d.i. wetenschappelijk vast staan, voor en aleer men zich met de huidige ordening, waaruit de groote, ontzettende oorlog voortkwam, tevreden stelt." Prof. Bordewijk stelle zich gerust en wel om de volgende redenen: 1. Het liberale socialisme staat - zoowel theoretisch als praktisch - ver boven het achterlijk en onrechtmatige Marxisme en communisme. Zijn richtsnoer is niet macht en roof, doch het natulurrecht, zoodat het onteigening zonder schadeloosstelling ten strengste afkeurt. 2. Men kan derhalve zeer wel de uitbuitingstheorie aanhangen en niettemin de anmuleering der Russische staatsschuld verwerpelijk achten. 3. De uitbuitingstheorie der rente staat onomstootelijk en wetenschappelijk vast voor ieder, die inziet, dat de rente uit bezitsverhoudingen moet worden verklaard en weet, dat die verhoudingen voor een zeer groot deel door grof onrecht zijn veroorzaakt: Uitbuiting en in den loop der tijden gepleegd onrecht hangen onverbrekelijk samen. En vandaar het onhoudbare standpunt van de burgerlijke theoretici, die weliswaar het historisch onrecht toegeven, doch de uitbuiting niettemin loochenen. En vandaar ook het standpunt van schrijver dezes, die de mogelijkheid van rechtvaardige rente zonder voorbehoud erkent. Het tegen rente uitleenen van door arbeid gewonnen goed van den voorzichtige aan den ondermemende treft geen blaam.

Quintessens van deze en andere twistpunten blijft echter, of en in hoeverre door gelijkmatiger rijkclomsverdeeling de rente daalt, het loon rijst, de welvaàrt toeneemt en aan de nawerking van vroeger gepleegd onrecht een eind kan worden gemaakt.

Wie over deze quintessens zwijgt schiet in zijne bestrijding van het liberale socialisme te kort.

Het merkwaardigste in Prof. Bordewijk's artikel is wel het slot, 
waarin de schrijver uiting geeft aan zijn verontwaardiging over O.'s vreugde, dat bij dalenden rentestand het rentetype van de Staatsleeningen naar beneden kan worden gekonverteerd. Gelet op het feit, dat reeds jarenlang in de Nederlandsche leeningwetten (evenals natuurlijk in tal van andere) de bevoegdheid tot vrijwillige konversie uitdrukkelijk is voorbehouden, werkt deze verontwaardiging wel ietwat op de lachspieren. Prof. Bordewijk kan ervan overtuigd zijn - ik heb als ambtenaar van het Departement van Financiën mijne desbetreffende inlichtingen uit zeer goede bron dat bij een algemeene daling van den rentestand, van die bevoegdheid weldra zal worden gebruik gemaakt. Wat blijft er in dit verband over van de bewering van Prof. Bordewijk, dat het geloofsartikel der uitbuiting tot het plegen van het grofste onrecht verleidt. Sedert wanneer is de vrijwillige konversie, gebruikmaknng van een uitdrukkelijk voorbehouden bevoegdheid, grof onrecht en berooving ? Waarlijk de verblinding is hier enkel aan den kant van Prof. B., geenszins bij Oppenheimer.

Dit slot geeft mij vrijmoedigheid met een enkel woord in te gaan op noot 50 van blz. 115 van II, waar Prof. B. mijne zienswijze, dat sinds het ontstaan der economische wetenschap een respektabel aantal drogredenen heeft moeten dienst doen om de klassebelangen eener heerschende groep te stutten een verdachtmaking noemt in een wetenschappelijk geschrift misplaatst, voortvloeiend uit onverdraagzaamheid, die voorzit in stee van de erkenning, dat wetenschap waarheid zoekt. Met dit laatste is mijne stelling niet in strijd. En hoe weet Prof. B. zoo zeker, dat wetenschap steeds waarheid zoekt. Blikt hij zoo diep in het bewuste en onderbewuste zieleleven van de wetenschappelijke onderzoekers? En hoe verklaart hij b.v. de bekende theorie van Schopenhauer over het recht anders dan uit jaloerschheid tegen Hegel? En de schandeliike gedragingen van eerste-rangs natuurkundigen tegenover R. Mayer anders dan uit nijd ? Ik wensch niemand van opzettelijke oneerlijkheid te betichten, maar evenmin op gezag van Prof. B. aan te nemen, dat een onderzoeker, bewust en onderbewust, steeds enkel de waarheid op het oog heeft. Dit te minder, omdat mij bij de kritiek van Prof. B. tegen Sax en O. uit meer dan één plaats (I blz. 75, 77, 82, 91, 102, 103, 104, 106, 1I, 13, 96, 106, 108, 110, 111, III blz. 601) blijkt, dat mijn hooggeleerde tegenstander dit zelf niet aanneemt. Hoe anders te verklaren zijn uitspraak op blz. $82 \mathrm{nt}$., om van andere plaatsen verder te zwijgen, ,Het kost 
anders te doen dan mij te refereeren aan mijn Robinsonade. Het komt mij nog altijd voor, dat ik in bedoeld artikel het wetenschappelijk bewijs geleverd heb, dat een Robinson, ook vóór hij in Vrijdag een uitbuitingsobject krijgt, aan het renteverschijnsel niet ontkomt. Mijn bewijs steunde op een combinatie van agio- en toerekeningstheorie. De geachte schrijver ziet hier een gevaar. Ik had mij tot voorzichtigheid mocten laten stemmen, immers de toerckeningstheorie zou alleen de rente op het terrein der voortbrenging, maar niet die uit geldleening kunnen afleiden. Maar nu kan ik er toch werkelijk niets aan doen, dat ik hier geen gevaar onderken. Want het kader van mijn stuk was door Robinson getrokken. Deze merkwaardige figuur kon wèl produceeren, maar niet uitleenen. En nu beteekent verder, als wij overgaan tot menschen-in-samenleving, die uitleenrente voor het renteprobleem niets hoegenaamd. Het kont alleen aan op de oorspronkelijke rente, ') waaruit de leenrente, als volkomen afluankelijk wij! afgeleid, wordit gekweten. De vraag, die ik moest onderzoeken. betrof het al dan niet voorkomen van oorspronkelijke rente ook bij Robinson. Zóó alleen kon tot de kern van het vraagstuk worden doorgedrongen. Alleen wie dwaalt op de wijze der canonici met lun rentebeperking tot geldsommen, kan meenen, dat de tocrekeningsleer ontoereikend zou zijn, wanneer zij aan den „Darlehenszins" wordt getoetst.

Ten overvloede wil ik wijzen op eenige plaatsen bij v. Böhm waar deze evenzeer agio- en toerekeningstheorie als elkaar aanvullend hanteert, zoo P. T. blz. 568 van den $3 e n$ druk inzake het bewijs van een zuilere pachtwaarde. De toerekening van Ricardo kwam slechts tot een bruto-bedrag, de agioleer weet daaruit het netto-bestandcleel los te wikkelen. Dan b.v., waar op blz. 563, noot 3 v. Böhm de waarde van productiegoederen in het algemeen vindt, ,nach Abrechnung des Anteils der mitwirkenden komplementären Faktoren". Vgl. verder blz. 285 v., waar de waardeberekening der complementaire goederen via toerekening plaats heeft, maar tevens wordt geconstateerd, dat t.a.v. kapitaal deze methode slechts leidt tot een „Rohzins”, zoodat het renteverschijnsel, dat een nctto-bate betreft, nog niet is opgehelderd. Inderdaad is dus het gevaar, dat tot voorzichtigheid zou moeten stem-

1) Zooals niet ik, maar jedereen, die onderscheidingsvermogen bezit en let rentevraagstuk behandelt, nil Böhm hall zal "gelieven" te noemen. 
zondaren te onderscheiden, met het gevolg, dat geen zondaar zóó. zwart is als de zonde zelve of met dat anclere verstrekkende gevolg, dat de zonde met haat en de zondaar met liefde moet vorden bejegend, zoo goed is er verschil tusschen de wetenschap, voor welke de waarheid het één is en het al, en de wetenschappelijke onderzoekers, die niet altijd trouwe fakkeldragers zijn gebleken. Ik geneer mij haast, deze waarheid als een koe neer te schrijven, doch ik word door de verwarring bij den schrijver daartoe genoopt.

Ten slotte mijn verontwaardiging over de wijze, waarop Oppenheimer omspringt met de goede trouw in zake de Staatsleeningen. Ik constateer, dat ook op dit punt de werking op des schrijvers lachspieren het gevolg is van onvoldoend onderscheiden. Conversie tot lager rentetype is iets anders dan hetgeen Oppenheimer wil. Want bij conversie krijgt de geldschieter de hoofdsom vol terug en profiteert de Staat alleen van de algemeene daling van den rentestand. De conversie van Oppenheimer zal echter ,,in absehbarer Zeit" tot $1 \%$ gaan. Wie, die begrip heeft van het altijd tegenover de absolute behoefte nijpende kapitaal-tekort, kan hierin iets anders zien dan annuleering met behoud van een al te doorzichtigen schijn? Hoe weinig vast Oppenheimer op dit punt is, toont dezelfde blz. 53 van ,Der Ausweg”, waar hij eerst zegt, dat de kapitalist, wegens onmogelijkheid van belegging elders, zijn geld niet kan terugvorderen, om onmiddellijk daarop te gewagen van den „Erlös", d.i. de opbrengst, van het wèl opgevorderde geld. Van tweeën één: òf het kapitaal gaat onder het liberale socialisme vrijwel tot de „vrije” goederen behooren, daar de rente nagenoeg verdwenen is (één per mille !); òf de kapitaaldienst blijft tegenover de behoefte een waardevol goed, maar dan beduidt een conversie à la Oppenheimer confiscatie van kapitaal. De laatste onderstelling is de eenig aannemelijke. Immers de door het wegvallen der meerwaarde naar het heet vermeerderde consumtieen koopkracht zou de behoefte aan kapitaal eer doen toe- dan afnemen. Waarom zou, bij het verdwijnen van den ,,Rrofit", daartegenover de kapitaalvorming sterker zijn dan thans? Van den Profit, die, naar van socialistische zijde wordt erkend, in de bestaande orde, behoudens hetgeen de belastingen daarvan nemen, goeddeels wordt belegd?

En hiermede neem ik afscheid van den schrijver, van wiens theorieën met volle recht kan worden getuigd, dat zij haar steun 